\title{
Do pensioners endanger fiscal stability in EU countries?
}

Received (in revised form): 21st September, 2008

\section{Jože Mencinger}

obtained his PhD from the University of Pennsylvania. He is a professor of economics with the Law School, University of Ljubljana. He served as Deputy Prime Minister, Republic of Slovenia from 1990 to 1991. He was a member of the board of governors, Bank of Slovenia from 1991 to 1997. He also served as the rector of the University of Ljubljana from 1998 to 2005.

\begin{abstract}
One of the rarely questioned 'truths' in the present cycle of conventional economic thinking is that ageing and pensioners are endangering the fiscal stability of EU countries. Yet, the data indicate that despite a considerable increase of the debatable old age dependency ratio, the shares of pensions in gross domestic product in EU countries stabilised due to the developments in their determinants: the retirement age, the replacement rate, the old age ratio and the development level. This indicates that the threats of 'greedy' pensioners to fiscal stability are highly exaggerated and that solutions for the ageing of the EU population can be found within the existing pay-as-you-go systems, provided there are jobs available. The demographic, 'Lisbon' and financial directions of the European Commission appear to be rather extraneous. Indeed, increased birth rates and migrations might produce more problems than solutions: job creation by the Lisbon strategy seems to consist of empty talks, while changing financing patterns and privatisation would only create redistribution without increasing the funding.
\end{abstract}

Pensions (2008) 13, 227-235. doi:10.1057/pm.2008.28

Keywords: economics of the elderly, public expenditures, pensions

\section{Introduction}

One of the rarely questioned 'truths' in the present cycle of conventional economic thinking is that pensioners are endangering fiscal equilibrium and that they could cause the collapse of the fiscal systems. The 'paradigm' got momentum after a now famous report, 'Averting the old age crisis', ${ }^{1}$ was published by the World Bank in 1994. The main message of the report, that public pensions should be partially or fully replaced by private ones, has influenced the debates and has been behind substantial pension reforms in many EU countries, particularly new

Correspondence: Jože Mencinger, Law School, University of Ljubljana, Poljanski nasip 2, 1000 Ljubljana, Slovenia.

Tel: 386125216881

Fax: 38614256870

E-mail: joze.mencinger@pf.uni-lj.si member states (NMS). The importance of pension reforms for the sustainability of the fiscal systems has also been continually stressed by the European Commission. ${ }^{2}$ The debates on the collapse of public finance in 2050 caused by 'greedy' pensioners in a way resemble the well-known calculations by Robert Malthus when discussing limits of economic growth. That is, the fate of public finances in 2050 is most likely as uncertain today as Malthus`s predictions were 200 years ago. One thing is certain however : the Lisbon strategy, which is often stressed as a solution by European politicians and economists, will not solve the problem.

\section{Ageing, old age and young age dependency}

The debates on the threatening collapse of public finance begin with data on the ageing of the EU 
population indicated by the increase of the old age dependency ratio, that is, the ratio between number of persons older than 65 and number of persons between 15 and 64. The latter are supposed to bear the economic burden caused by the former. According to Eurostat, the numerator of the ratio, that is, the share of people over 65 , would in EU27 increase from 17.08 per cent in 2008 to 28.81 per cent in 2050 . At the same time, the denominator, the share of those in the age group 15-64 years, would shrink from 67.27 to 57.14 per cent. The resulting old age dependency ratio would thus grow from the existing 25.39 to 50.42 per cent. The share of people older than 65 would increase more in NMS (except for Baltic states), South European countries and Germany. Using the Eurostat demographic projections, the situation among NMS would be most critical in Slovenia, with an old age dependency ratio of 59 per cent, followed by Poland, Bulgaria, Slovakia, Czech Republic and Romania with ratios close to 55 per cent. In old member states (OMS), the situation would be the worst in Italy, followed by Spain, Greece and Germany. Extremes on the opposite side are Luxemburg, UK and Cyprus, with an old age dependency ratio of 38 per cent, followed by Sweden and Denmark. Let us assume that the demographic figures for 2050 are quite accurate; the figures in the numerator are easy to calculate, while the figures in the denominator are only slightly less certain, which means that the value of the indicator - the old age dependency ratio is rather precise. The sole definition, that is, the boundaries of the numerator and the denominator, are, however, debatable. Both should be moved upward - old age boundary for at least five years and 'young age dependency' boundary for ten years. This might make the old age dependency ratio even more worrisome, but would make it more realistic. Jobs have changed. It is true that most workers who began working in manufacturing or mining 30 or 40 years ago are exhausted at the age of 65 . This, however, is not the case now: people may be fed up with what they are doing but they are not exhausted. On the other hand, very few people start working before the age of 25 . The average education level and the number of those enrolled in tertiary education in the EU has increased dramatically. The passage from education to the labour market has altered: the age at the passage has been increasing and getting less certain as the traditional employment pattern is being more frequently replaced by different forms of precarious employment. A shrinking share of 'young' population in the total population and the extension of tertiary education have reduced the potential supply of 'young' labour force, though reductions on the supply side have been to a large extent annulled by the changes on the demand side governed by labour-saving technological changes and a changing labour demand structure.

It is also true that the statutory retirement age ${ }^{3}$ is even lower than the old age dependency boundary, and also that many people retire much earlier. However, the effective retirement age in the EU is moving upward. Between 2001 and 2007, the effective retirement age in EU27 increased from 59.9 to 61.2 , in EU15 it raised from 60.3 to 61.4 , and in NMS from 57.6 to 58.9. The upsurge in the effective retirement age in the EU and a convergence of NMS retirement age to EU retirement age could continue, ${ }^{4}$ which would increase the supply of labour. Indeed, many more problems seem to exist on the demand side of the labour market than on the supply side, that is, whether enough jobs can be created for those who would like to postpone retirement. One can ask a more general question. Can EU in the long run create enough productive jobs for its population, young or old?

\section{Pensions}

Expenditures for pensions or transfers from the active population to pensioners are supposed to be the root of the problem. Yet, the data reveal that despite a considerable increase in the old age dependency ratio between 1995 and 2005, the share of pensions in gross domestic product (GDP) in the EU stabilised or even decreased slightly, indicating that the growth of the average pension lagged significantly behind GDP growth.

There is a noticeable diversity in the share of pensions in GDP among EU member states; the 
Table 1: The determinants of the share of pensions in EU countries

\begin{tabular}{lcccc}
\hline $\begin{array}{l}\text { Dependent variable: Share of pensions in GDP } \\
\text { Method: Ordinary least squares } \\
\text { Included observations: 25 }\end{array}$ & & & \\
& & & \\
\hline & Coefficient & Std. error & t-statistic & Prob. \\
\hline$b_{0}$ & 33.14 & 13.49 & 2.456 & 0.0233 \\
$b_{1}$ (Old age ratio) & 0.325 & 0.104 & 3.112 & 0.0055 \\
$b_{2}$ (Retirement age) & -0.656 & 0.217 & -3.024 & 0.0067 \\
$b_{3}$ (Development level & 0.052 & 0.013 & 3.995 & 0.0007 \\
$b_{4}$ (Replacement ratio) & 0.095 & 0.045 & 2.096 & 0.0490 \\
$R$-squared & & & & 10.09 \\
Adjusted $R$-squared & 0.685 & Mean dependent var. & 2.755 \\
SE of regression & 0.622 & SD dependent var. & 57.32 \\
$F$-statistic & 1.693 & Sum squared residuals & -45.84 \\
\hline
\end{tabular}

Source: Eurostat.

share in Italy is, for example, three times higher than in Ireland. Italy, with the highest share, is followed by Austria, France, Germany, Netherlands, Poland and Sweden, while Ireland, with the lowest share, is followed by Estonia, Romania, Latvia and Lithuania. The share of pensions in GDP in NMS (except Slovenia and Poland), particularly in three Baltic states (Estonia, Latvia and Lithuania), is considerably lower than in EU15: pensioners in NMS countries were apparently among the major victims of transition.

The share of pensions in GDP in a country depends on its pension system, which is influenced by the age of population, retirement age, replacement rate ${ }^{5}$ and the level of economic development. The retirement age and the replacement rate reflect the existing pension system, the old age ratio reveals the needs for pensions expenditures, and the development level shows fiscal capacity, that is, the capacity of the country to provide financing. Thus, an upward shift in the retirement age would decrease the share of pensions in GDP, whereas the replacement rate, ageing of the population and the level of economic development should increase the share. For the most recent period for which data are available, the determinants of the European pension systems can be summarised by a regression equation in which the share of pensions in GDP is the dependent variable and the retirement age, replacement rate, old age ratio and level of GDP per capita are independent variables (Table 1 ).

$$
\begin{aligned}
\text { Pensions / GDP }= & b_{0}+b_{1} \times \text { Old age } \\
& +b_{2} \times \text { Retirement age } \\
& +b_{3} \times \text { GDP } / \text { capita } \\
& +b_{4} \times \text { Replacement rate }
\end{aligned}
$$

According to the equation, a one percentage point rise of the old age ratio increases the share of pensions in GDP by a 0.325 percentage point, the rise of replacement rate increases the share by a 0.095 percentage point, and the increase in effective retirement age decreases the share by a 0.656 percentage point. Furthermore, the share of pensions in GDP grows by the level of development ${ }^{6}$ (Figure 1).

The level of development and the age of population can be considered exogenous, whereas the retirement age and replacement rate can be treated as economic policy variables. The residuals might thus show the leftover relative 'kindness' and 'miserliness' of a country towards old people. Poland, the Netherlands and Cyprus are the most 'generous', whereas Estonia, Ireland, Spain, Latvia and Lithuania are the most 'thrifty'.

The differences in the retirement age among countries indirectly indicate the countries where 


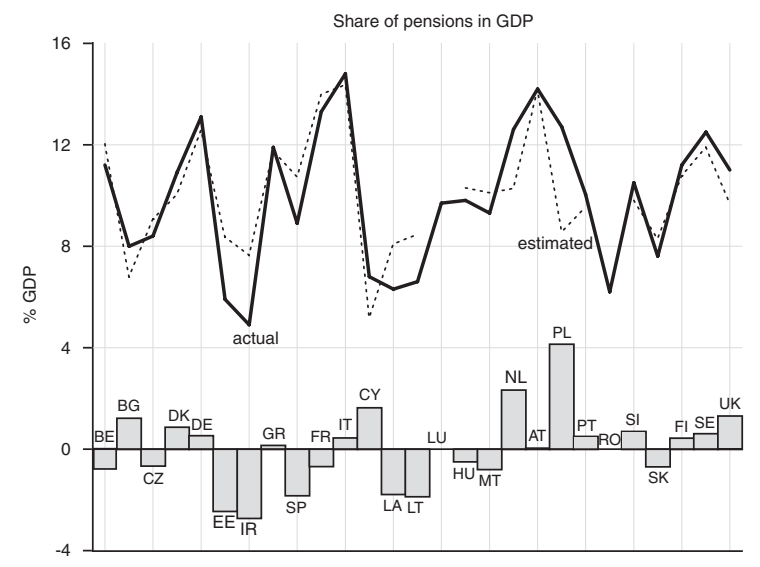

Figure 1: Actual and estimated shares of pensions in GDP

the share of pensions in GDP could be lowered by increasing the retirement age to the existing EU27 average: Malta, France, Italy, Lithuania, Luxemburg, Hungary, Poland, Slovenia and Slovakia. Bulgaria, Ireland, Romania and Sweden have a much higher retirement age than the EU27 average; hence they have already used some of the potential increase of the retirement age to reduce expenditures. An alternative to increasing the retirement age is lowering the replacement rate; the potential to implement this idea exists in Austria, Luxemburg, Sweden, Bulgaria, Portugal, Poland, Italy and France, where replacement rates considerably exceed the EU27 average.

The equation indirectly indicates that the threats of 'greedy pensioners' to the fiscal balances in the EU as a whole and primarily in NMS are highly exaggerated. First, the substantial differences among EU countries regarding the shares of pensions and their economic policy determinants (retirement age and replacement rate) instinctively indicate that possibilities for adaptation exist. Secondly, the lagging NMS are growing relatively fast and their GDP/capita converge to the EU average, which would enable higher shares of pensions in GDP. Economic growth directly lessens the share by increasing the denominator, and indirectly by facilitating the redistribution of incomes from the active population to pensioners. Thirdly, while ageing cannot be avoided, the effects of ageing can be
Table 2: Public spending on old-age pensions, 2000 and 2050 (in per cent of GDP)

\begin{tabular}{lrrr}
\hline & 2000 & 2050 & $\begin{array}{l}\text { Change in } \\
\%\end{array}$ \\
\hline $\begin{array}{lrr}\text { France } \\
\text { Italy }\end{array}$ & 12.1 & 14.5 & 19.8 \\
Germany & 14.2 & 14.4 & 1.5 \\
Belgium & 11.8 & 13.8 & 17.0 \\
Sweden & 9.0 & 13.0 & 44.4 \\
Netherlands & 9.2 & 10.8 & 17.4 \\
UK & 5.2 & 8.3 & 59.6 \\
USA & 5.0 & 5.6 & 12.0 \\
Japan & 4.4 & 6.2 & 40.9 \\
Canada & 7.9 & 8.5 & 7.6 \\
Switzerland & 4.7 & 6.4 & 36.2 \\
\hline
\end{tabular}

successfully countered by increases in the retirement age, provided that there are incentives to postpone retirement and that there are jobs available. ${ }^{7}$ The postponement of retirement ${ }^{8}$ appears to be the most efficient way to prevent financial strain. It has a twofold effect: it increases the payments to the pension funds and, even more importantly, reduces the expenditures (the number of pensioners and the number of years a pensioner collects the pension). For example, by prolonging the retirement age from 60 to 65 years of age, the contributions to the pension funds would increase inflows and reduce outflows by at least 10 per cent each; the average life expectancy in the EU at 60 is namely 21.2 years, at 65 it is 17.2 years. The incentives to postpone retirement can therefore be easily made financially attractive. Fourthly, the sole fact that since 1990 the shares of pensions in GDP in old EU states fluctuated around country-specific averages (they have increased significantly in Austria, Italy and Portugal, and have decreased in Belgium, Luxemburg and the Netherlands) indicates that there has been no real worsening of the financial state, which implies that there is no need for radical changes to the existing systems. This is indirectly confirmed by the OECD calculations on the amount of public spending on old age pensions in 2000 and 2050, provided that the systems do not change. These calculations should serve as confirmation that changes are needed. Indeed, the figures in 
Table 2 are astonishing, but they (if realistic) are astonishing because of modest rather than large changes in public spending over a period of half a century. That is, despite upward convergence, public spending of most countries would in 2050 not reach the existing public spending in Italy.

'Greedy' pensioners are apparently less dangerous than suggested. Furthermore, when discussing the flows of money between generations, one should also add the flows of money, services (child care, etc) and wealth (inheritance) in the opposite direction, that is, from the 'old' generation to the 'young' generation. These flows are completely neglected in the discussions.

Pensioners are also supposed to 'be destructive' to the public financial system indirectly because of increased public expenditures for their healthcare. The demand for healthcare certainly increases with age. Again, the shares of healthcare expenditures in EU countries differ, with the share in France being nearly three times higher than that in Latvia. The shares of healthcare expenditures in GDP are on average much lower in NMS than in more developed 'old' member states. Healthcare therefore appears to be another victim of transition in NMS.

Healthcare services are by definition a component of value added and therefore their growth automatically contributes to GDP growth. Inquiry in this direction would bring us again to the question of the limitlessness of economic growth and to GDP definitions. One can also assume that there is enough room for increasing the share of healthcare services in GDP in EU27. That is, the share of predominantly private healthcare (which, according to prevailing beliefs, should be more efficient than public healthcare) in GDP in the USA is approximately twice the share as that in the EU, although a large part of the population in the USA has no access to it. The studies also indicate that the predominant part of the increase in healthcare expenditure in the USA from 5 per cent of GDP in 1950 to 16 per cent in 2000 was not connected to the ageing of the population but rather to technological changes in healthcare services. ${ }^{9}$

\section{EU 'solutions' to the problems}

The EU Commission (EC) observes that the EU
'has to cope with demographic decline, low natural growth and the ageing of its population. To respond to this challenge, the Commission sets out a number of recommendations drawing mainly on the renewed Lisbon strategy to take full advantage of longer lives, whilst also sparking of demographic renewal'... 'Rigorous implementation of the Lisbon agenda should help this corner by making full use of the resources of experienced workers whilst also offering younger people quality training'. (Communication of the EC from October 12th, 2006, 'The demographic future of Europe - from challenge to opportunity')

The EC outlines five directions to meet these challenges:

- promoting demographic renewal by improving the balance between professional, private and working life;

- promoting employment in Europe through more jobs and longer working lives by improving education systems and prioritising 'flexicurity' systems;

- a more productive and dynamic Europe thanks to the refocusing of the Lisbon strategy since 2005;

- receiving and integrating immigrants in Europe by working together with member states to develop a common policy on legal immigration to attract a qualified labour force from outside in order to meet the needs of its labour market;

- sustainable public finances in Europe to guarantee adequate social protection and equity between the generations in most member states, budgetary restraint is absolutely essential, particularly when reforming the pensions system. There will also be a need to link the coverage of these systems with the level of contributions to the development of private saving and funded systems.

Three types of directions can be distinguished: demographic, 'Lisbon' and financial. 


\section{Demographic directions}

Demographic renewal by improving the balance between professional, private and working life implies increasing birth rates to rejuvenate the European population. Yet, it is unlikely that birth rates can be considerably influenced by 'demographic policies' acceptable in a normal democratic country, and it is certain that the increase in birth rates would strongly increase young age dependency, particularly because newly born EU citizens would enter the labour market at the age of 25 or 30 rather than at the age of 15. The real old age dependency would be affected much later.

Migration is another demographic 'solution'. According to this idea, the ageing problem in EU countries could be solved through immigration from countries with younger populations, which would alter the age structure and increase payments to pension funds. The potential positive effects of migration are, however, highly overstated and long-run negative economic and social impacts on both emigrant and immigrant countries are overlooked. The demographic situation in the EU countries indicates that the share of people of working age (15-64), which is 67.27 per cent, does not differ considerably among EU countries: it is the highest in Slovakia, with 72.26 per cent of the population and the lowest in Sweden, with 65.7 per cent. There is thus not much additional room for migration flows within EU. Furthermore, immigration to a country to decrease its old age dependency ratio implies emigration from another country and the growth of its old age dependency ratio. The severing of family bonds through emigration also increases the need for government care for old people who could otherwise stay partly independent if helped by their children. Indeed, the migration flows from some NMS might soon create unbearable situations; the three Baltic countries (Estonia, Latvia and Lithuania) have, since transition and despite high economic growth, lost up to 15 per cent of their population and a much higher percentage of their most able working population without a considerable increase in remittances.

Can migrants from elsewhere contribute to sustainable development in the EU? Again, leaving aside the fact that through emigration the native country loses its most able citizens, there are more questions than answers for the host countries. First, the successful participation of immigrants in the labour markets of the EU countries is uncertain. Indeed, immigrants are most often low-skilled workers who do not match the needs of the host countries, and unemployment rates among immigrants in EU countries are systematically much higher than among nationals. This might add to rather than reduce the strain on social security systems. Secondly, according to the estimates by the EC, the EU would need almost 90 million labour migrants for the period 2005-2050, or two million a year. This would create an unbearable social and cultural situation in the host countries; one cannot consider migrants as simply cheap labour force. Thirdly, xenophobia in EU countries has been on the rise and would strengthen during economic slowdown or recession. Developing a common EU policy on legal immigration to attract qualified labour from outside in order to meet the needs of the EU's labour market seems to be at best utopian.

\section{The Lisbon 'solution'}

Modern societies and governments are preoccupied with efficiency and economic growth, which are taken as limitless due to enhanced total factor productivity and the prevalence of services rather than production of goods. The EU condensed this preoccupation in the Lisbon strategy signed in 2000. This strategy was designed to ensure that Europe becomes the most efficient knowledge-based society of full employment to compete in the globalisation contest. After some years of mantras on the strategy, actual development and the report of the Wim Kok committee at the end of 2004 brought some soberness and indirect admittance that the EU was not only far from the Lisbon goals for 2010, but was also heading in the wrong direction. The EC reluctantly admitted that the Lisbon strategy had failed and in February 2005 the 'old' strategy was replaced by 'Partnership for Growth and Jobs - New Beginning of the Lisbon Strategy'. In this new version, the ending 
year 2010 was abandoned, the number of goals was reduced and responsibilities were turned to the governments of member states; the new strategy was said to be simple, pragmatic and tangible.

The 'scientific' pillar of the strategy is production function. Let us consider, for simplicity, that it has the form of Cobb-Douglas production function $Y=A \times K^{a} \times L^{b}$. This simply says that one must work $(L)$ and have machinery $(K)$ to produce $(Y)$; ' $a$ ' and ' $b$ ' indicate how changes in $K$ and $L$ affect $Y$. Growth, which cannot be explained by the increases in $K$ and $L$, is attributed to technological change or total factor productivity, embodied in ' $A$ '. ' $A$ ' provides ample room for empty talks on development, human capital, use of knowledge, entrepreneurship, efficient and inexpensive state administration, etc.

The Achilles' heel of the Lisbon strategy, the old and the new one, is total neglect of aggregate demand and full reliance on the premises of supply-side economics, according to which demand automatically equals supply. This is evident from the implicit central position of production function in the strategy, which is strange because the causality implied by the production function is not very relevant in an economy in which producers are much more concerned with how to sell products and services than with how to produce them. This implies that aggregate demand and aggregate employment functions are much more relevant for determining output, investments and employment.

The argument that increased production will decrease costs, leading to a drop in prices, increased demand and additional supply of other goods and services is relevant in a frictionless and timeless world, but less relevant in reality. Technological changes have indeed transformed into economic growth and a tremendous increase in the standard of living. They should, according to the strategy and in combination with a more flexible labour market, also bring more and better jobs and a transfer of workers from jobs with low value added to jobs with high value added, thus lowering unemployment. But while technological changes undoubtedly increase productivity and create better jobs, they, at least directly, do not create more jobs. Their total effects on employment are combinations of different processes, some reducing, others enhancing employment. That is, most technological changes are labour-saving and new jobs created by technological changes in a specific industry, in which changes emerge, are most likely fewer than jobs that are eliminated. Only some workers who lose jobs because of technological changes can find new jobs in the same industry or in other industries producing material goods with higher value added. Some of these workers move to the service sectors with the same, higher or lower value added jobs, while some of them become unemployed. Indeed, technological changes that directly reduce jobs indirectly enable the creation of new jobs in services, public or private, with the same, higher (public servants, lawyers, etc) or lower (waitresses, garbage workers, etc) value added, or enable the survival of those left without jobs, including pensioners.

It is easy to see that attributing new jobs in the $\mathrm{EU}$ to the Lisbon strategy is nonsense. That is, in the last decade, all new jobs in the EU were created in services; in the period 1997-2005 a total of 13 million jobs were created, 16 million in services; 2 million were lost in industry and 1 million jobs were lost in agriculture. In addition, the central role of job creation in many countries belonged to employment in the public sector or in recently privatised public services. ${ }^{10}$ How the Lisbon strategy could contribute to solving pension problems therefore remains unclear.

\section{Financial directions}

The existing pension systems in EU countries have been, despite a great number of permutations in existing institutions, ${ }^{11}$ more or less mixtures of the Bismarckian and Beveridgean principles: they combine the principle of linking the benefits to the contributions with the principle of basic solidarity. ${ }^{12}$ This has not changed regardless of the many pension reforms enacted in the last 15 years. Thus, in the real world, we have different combinations of a compulsory, categorical system with benefits strongly linked to contributions and substantial 
replacement rate (Bismarckian), and universal membership, a weak link between contributions and benefits, and low replacement rate (Beveridgean). While in the Bismarckian system the first pillar enables the maintenance of the normal survival of pensioners, second and third pillars are needed to maintain the working age living standards in the Beveridgean system. The pension reforms have not altered these features. ${ }^{11,13}$

Budgetary restraint, linkage of the coverage to the level of contributions, and development of private savings and funded systems belong to financial directions suggested by the EC. That is, according to the EC, small adjustments to the public pay-as-you-go (PAYG) systems alone cannot guarantee adequate social protection and equity between the generations or the sustainability of the pension systems. It is, however, not at all obvious that directives could provide solutions; they would create redistribution without increasing funding. ${ }^{14}$ The fully funded system is also affected by a shrinking active population, and the shift from the PAYG system to the fully funded system would bring unbearable burden to the currently active generation: it would request higher contributions and/or lowering of the existing contributions to the first pillar. ${ }^{15,16}$ Strengthening the linkage between contributions and benefits would establish a new distribution of payments and benefits. The second pillar based on the expected growth of financial wealth managed by public or private pension funds implies sharing the ups and downs of the world financial market ${ }^{17}$; a lot of capital would most likely disappear in the many 'black holes' of the financial systems.

The privatisation of the pension system, which is being considered as a promising option, also does not solve the problem. ${ }^{14}$ It does not assure or even promise secure income for the elderly. On the contrary, the increased choice and higher returns that are considered to be the advantages of the private pension funds cannot be achieved without enormous risks, which the majority of people cannot afford and are not even aware of. The market does not guarantee returns and neither does it guarantee that the value of financial investment will remain unchanged; transaction costs of private pension funds are higher than transaction costs of public pension funds. The care for the 'old' can also not be simply shifted from the public to the private sector. Indeed, the consequences of privatisation could be catastrophic both for the pensioners and for public finance. If the private pension fund collapses, the government cannot avoid responsibility for the pensioners affected by the collapse of the fund, which would leave many old people in poverty. Furthermore, while the division of economic and other activities into those that should be predominantly private and those that should be public, is a matter of value judgments, it is also evident that the countries with a higher share of public sector in GDP are not less successful than the countries with a lower share of public sector in GDP.

In short, one could say that the funding troubles of the EU public PAYG pension system have been greatly exaggerated, which coincides with Joseph Stiglitz`s inference on US Social Security. ${ }^{18}$ Indeed, solutions for the ageing of the EU population can be found within the existing PAYG systems.

\section{References and Notes}

1 World Bank (1994) 'Averting the Old Age Crisis', World Bank, Washington.

2 See for example: 'The demographic future of Europe - from challenge to opportunity' COM(2006) 571; Green Paper 'Confronting demographic change; a new solidarity between the generations' COM(2005) 94; or 'The Future Evolution of Social Protection from a Long-Term Point of View: Safe and Sustainable Pensions' $\operatorname{COM}(2000)$ 622. The problems related to public financing of pensions are considered particularly grave in the NMS. According to EU, three groups could be formed. Slovenia would together with Hungary and Czech Republic belong to the countries with 'high risk', Slovakia would be among the countries with 'medium risk' while Poland would be the country of 'low risk' due to the pensions reform, by which public financing of the system was transferred to private financing.

3 Average exit age from the labour force - weighted by the probability of withdrawal from the labour market.

4 Namely, early retirement was during transition in NMS used as a socially more acceptable alternative to firing workers.

5 Replacement rate is defined as the ratio of income from pensions of persons aged between 65 and 74 years and income from work of persons aged between 50 and 59 years.

6 Two countries Romania and Luxemburg are omitted from the equation; Romania because there are no data on the 
replacement rate, Luxemburg because of its extreme value of GDP/capita.

7 Economic growth should be according to modern growth theories limitless because it is based on knowledge and growing share of services in GDP; knowledge has no limits, while new and new services which already exceed 70 per cent of GDP could be invented without affecting limited natural resources. It seems, however, that mankind is forced to invent new and new services to create jobs and incomes for those who are pushed out of traditional economic activities by labour-saving technological change. The root of the problem is therefore not in the ageing of the population but in the limitlessness of economic growth and its job creation ability.

8 Gruber, J., in and Wise, D. (2002) 'Social security programs and retirement around the world: Micro estimation', NBER Working Paper No. 9407.

9 Hagist, C. and Kotlikoff, L. (2005) 'Who's going broke? Comparing growth and healthcare costs in ten OECD countries', NBER Working Paper No. 11833.

10 European Commission nevertheless assumes that liberalisation of the labour market would create more jobs. This is a controversial assumption; liberalisation of the labour market is to increase efficiency which implies that the same amount of public services could be provided by fewer public servants.
11 Werding, M. (2003) 'After another decade of reform: Do pension systems in Europe converge?' CESifo DICE Report, Vol. 1, No. 1, pp. 11-16.

12 The countries with Bismarckian tradition are Austria, Belgium, Germany, Greece; Italy, Luxemburg, Portugal and Spain, while the countries with Beveridgean tradition are Ireland, the Netherlands and UK. Elements of both are most recognised in Denmark, Sweden, Finland and France.

13 'The reforms observed in our sample of countries indicate, that over the last decade there has been some convergence with respect to a number of basic features of how public pension systems are operated; the idea of actuarial fairness has moved to the fore, and systems with defined contributions have become wide spread. Yet, this does not imply that the systems converge to just one, uniform model' (Werding, ${ }^{11}$ p. 14).

14 Huffschmid, J. (2007) 'Finance-Privatization-Regulation', EAPEPRESOM Conference, Delft, 22nd March, 2007 (mimeo).

15 Bole, V. (1998) 'Financing the transition of the public pension system in Slovenia', Ministrstvo za finance RS, 25 pages (mimeo).

16 This was the main argument for refusing the proposed three pillars-based pension reform in Slovenia in 1999.

17 Poterba, J. (2005) 'Does population ageing affect financial markets ?', NBER Working Paper No. 10851.

18 Stiglitz, E. J. (2005) 'Securing social security for the future', The Economists' Voice, Vol. 2, No. 1, Article 5, pp. 1-7. 